TẠP CHÍ KHOA HỌC ĐẠI HỌC TÂN TRÀO

ISSN: $2354-1431$

http://tckh.daihoctantrao.edu.vn/

\title{
Giải pháp nâng cao nhận thức của xã hội về vai trò và tầm quan trọng của di sản thế giới
}

\author{
Bùi Hoài Sorn ${ }^{a^{*}}$ \\ ${ }^{a}$ Viện Văn hóa Nghệ thuật quốc gia Việt Nam \\ Email:sonmqq@yahoo.com
}

\section{Thông tin bài viết}

Ngày nhận bài:

20/7/2018

Ngày duyệt đăng:

$10 / 9 / 2018$

Tù khoá:

Di sản thế giới, du lịch di sản, quản lý văn hóa, cộng đồng.

\section{Tóm tắt}

Hiện nay, Việt Nam đã được UNESCO công nhận nhiều di sản thế giới. Tuy nhiên, việc công nhận di sản mới chỉ là giai đoạn ban đầu, hoạt động bảo tồn và phát huy giá trị di sản, để di sản có đóng góp tích cực trong việc phát triển kinh tế - xã hội mới được xem là có ý nghĩa phục vụ sự phát triển bền vững đất nước. Từ việc phân tích về tầm quan trọng của di sản thế giới, bài viết tập trung chủ yếu đến giải pháp nâng cao nhận thức của xã hội đối với vai trò của di sản thế giới đối với sự phát triển kinh tế - xã hội của một địa phương nói riêng, cả nước nói chung từ những câu hỏi căn bản như: Nâng cao nhận thức của ai? Nâng cao nhận thức bằng cách nào?

\section{Mở đầu}

Đến thời điểm hiện nay (2018), Việt Nam đã có 8 di tích được công nhận là di sản thế giới ( 2 di sản thiên nhiên thế giới, 5 di sản văn hóa thế giới, 1 di sản hỗn hợp) và 12 di sản văn hóa phi vật thể, 9 khu dự trữ sinh quyển thế giới và $2 \mathrm{di}$ sản tư liệu thế giới, $4 \mathrm{di}$ sản tư liệu khu vực châu Á - Thái Bình Dương. So với các nước trên thế giới, Việt Nam là quốc gia chú ý nhiều đến việc tôn vinh di sản văn hóa dân tộc. Nhờ sự quan tâm của Đảng và Nhà nước đối với kho tàng di sản văn hóa, tài sản quý báu này ngày càng đóng vai trò tích cực đối với sự phát triển đất nước.

\section{Tầm quan trọng của di sản thế giới đối với sự phát triển đất nước}

Thứ nhất là tầm quan trọng của di sản thế giới đối với việc xây dựng thương hiệu cho 1 vùng đất và cả đất nước. Thương hiệu cho 1 di sản có tác dụng lan tỏa, không chỉ là minh chứng về một giá trị văn hóa mà còn tạo ra công ăn việc làm, sức mạnh mềm cho một vùng đất. Việc ngành văn hóa và các địa phương trình hồ sơ cho UNESCO công nhận các di sản thế giới nằm trong chiến lược chung xây dựng thương hiệu cho di sản. Xét ở bình diện toàn cầu, việc công nhận di sản thế giới được xem như sự xây dựng thương hiệu cho điểm đến, thể hiện sự giàu có và truyền thống lịch sử lâu đời của một nền văn hóa. Chính vì vậy, không chỉ Việt Nam, các quốc gia khác như Nhật Bản, Trung Quốc, Hàn Quốc, Pháp, Đức, Italia đều có chính sách rõ ràng về việc công nhận các di sản. Ở Việt Nam, việc công nhận các di sản như Hội An, Mỹ Sơn, Vịnh Hạ Long, Phong Nha - Kẻ Bàng (ở hạng mục vật thể) hay Ca trù, Quan họ... (ở hạng mục phi vật thể) thực sự đã khiến nhiều người có thêm hiểu biết về các di sản này. Từ những di sản đó, họ thêm yêu mến những vùng đất, con người và những giá trị văn hóa khác có liên quan đến di sản.

Thứ hai, công nhận di sản thế giới ở Việt Nam là minh chứng cho sự chăm lo của Đảng và Nhà nước đối với văn hóa nói chung, di sản của cha ông để lại nói riêng. Đất nước ta trải qua một thời gian dài chịu tàn phá của các cuộc chiến tranh. Nhiều di sản của đất nước bị mai một và biến dạng. Trong nhiều năm vừa qua, Đảng và Nhà nước quan tâm bảo tồn và phát huy giá trị di sản văn hóa thông qua các Nghị quyết Hội nghị lần thứ năm (Ban chấp hành Khóa VIII), Nghị quyết hội nghị lần thứ chín (Ban chấp hành Trung 
ương Khóa XI), hay các chương trình mục tiêu quốc gia về văn hóa, trong đó cụ thể có việc tập trung cho các di sản thế giới. Nhờ sự quan tâm đó, nhiều di sản văn hóa vật thể và phi vật thể được phục hồi và đóng vai trò quan trọng trong việc xây dựng đời sống tinh thần cho nhân dân cả nước. Có thể nói, phong trào toàn dân chăm sóc di sản văn hóa dân tộc đã được hình thành và trở thành mối quan tâm thường xuyên của không chỉ các cấp ủy Đảng, chính quyền các địa phương, mà quan trọng hơn là thấm sâu vào từng cộng đồng và người dân cả nước. Người dân cảm nhận được sự chăm lo của Đảng đối với truyền thống văn hóa của mình, nhờ đó gắn bó hơn với quê hương, đất nước, tăng cường tình đoàn kết cộng đồng, tạo điều kiện thuận lợi cho việc thực hiện các mục tiêu kinh tế - chính trị - xã hội của địa phương và cả nước. Minh chứng cho thấy rằng, ở đâu văn hóa được đầu tư, quan tâm, ở đó kinh tế phát triển, xã hội ổn định. Các ví dụ như Hội An, Hạ Long, Huế... cho thấy sức lan tỏa của việc bảo vệ và phát huy giá trị di sản thế giới với sự phát triển bền vững của một địa phương.

Thứ ba, tạo nên động lực phát triển kinh tế, xã hội ở một địa phương là giá trị quan trọng tiếp theo của di sản thế giới đối với một vùng đất. Như trên đã phân tích về việc hình thành thương hiệu cho di sản, khi các di sản này được biết đến rộng rãi, các di sản tạo ra giá trị lan tỏa ra các lĩnh vực khác. Chính vì vậy, du lịch di sản được xem là một trong lĩnh vực quan trọng của công nghiệp văn hóa trên thế giới và ở cả Việt Nam. Những con số biết nói từ du lịch di sản trong năm 2017 đã dẫn chứng cho nhận định này bằng số liệu 15,76 triệu lượt khách, trong đó có hơn 6,5 triệu lượt khách quốc tế với doanh thu khoảng 1.456 tỷ đồng đến từ các di sản văn hóa và thiên nhiên thế giới của Việt Nam, trong đó, "vịnh Hạ Long đón hơn 3,6 triệu lượt khách (trong đó 2,4 triệu lượt khách quốc tế), thu từ vé đạt khoảng 1.100 tỷ đồng. Quần thể danh thắng Tràng An đón gần 6,126 triệu lượt khách (trong đó gần 711 nghìn lượt khách quốc tế), doanh thu từ phí danh lam và phí chở đò đạt khoảng 652,2 tỷ đồng. Quần thể di tích Cố đô Huế đón khoảng 3 triệu lượt khách (trong đó hơn 1,8 triệu lượt khách quốc tế), thu từ vé hơn 320 tỷ đồng (tăng gấp bốn lần so với năm 2011, khoảng 80 tỷ đồng). Vườn quốc gia Phong Nha - Kẻ Bàng đón 810 nghìn lượt khách (trong đó 133 nghìn lượt khách quốc tế), doanh thu trực tiếp từ hoạt động du lịch khoảng 215 tỷ đồng. Khu phố cổ Hội An đón 1,96 triệu lượt khách (trong đó hơn 1,5 triệu lượt khách quốc tế), thu từ vé khoảng 219 tỷ đồng. Khu Di tích Mỹ Sơn đón hơn 350 nghìn lượt khách (trong đó hơn 300 nghìn lượt khách quốc tế), thu từ vé hơn 50 tỷ đồng." Đây cũng chính là một trong những lý do quan trọng khiến các địa phương đều mong muốn có được danh hiệu di sản thế giới để làm đòn bẩy phát triển kinh tế - xã hội cho địa phương mình.

Thứ tư, di sản thế giới có tác dụng đoàn kết cộng đồng, đoàn kết dân tộc. Khi bàn về vai trò của các di sản văn hóa, nhiều nhà nghiên cứu nhấn mạnh đến vai trò cộng mệnh, cộng cảm và cộng đồng của các di sản này. Trên thực tế, ở khía cạnh cộng đồng, các di sản văn hóa chính là một trong những lực gắn kết cộng đồng quan trọng nhất. Ý thức về tổ tiên luôn là nhân tố quan trọng để đoàn kết cộng đồng. Những lễ hội truyền thống ở các làng quê, những công trình kiến trúc cổ được xem là sợi dây liên kết các thành viên trong cộng đồng. Với các di sản thế giới, đặc biệt là những di sản văn hóa phi vật thể, sợi dây liên kết đó thể hiện qua việc các thành viên cộng đồng cùng nhau biểu diễn, thực hành và thưởng thức các loại hình nghệ thuật chung. Quan họ khiến người dân Bắc Ninh vừa cảm thấy tự hào, vừa cảm thấy gắn kết, và mỗi khi xa quê, họ tìm thấy đồng hương qua những câu hát Quan họ. Cồng chiêng Tây Nguyên giúp người Bahnar, M'nông, Jơ Rai tìm thấy bản sắc của mình qua lễ đâm trâu, mừng nhà mới, hay đơn thuần là quây quần cùng nhau quanh đống lửa múa xoang và chơi cồng chiêng. Những giá trị ấy nhất thiết phải được tôn vinh và truyền cảm hứng cho người dân trong cộng đồng, khiến họ tự hào và gìn giữ các truyền thống tốt đẹp của dân tộc, tạo ra sự đoàn kết, gắn bó với mảnh đất, con người nơi họ sinh ra, từ đó, tạo ra sức mạnh cho cả cộng đồng, dân tộc.

2. Giải pháp nâng cao nhận thức của xã hội về vai trò và tầm quan trọng của di sản thế giới

Những giá trị như trên đã phân tích là những nguồn lực vô giá từ di sản thế giới. Tuy nhiên, để phát huy các giá trị ấy đòi hỏi chúng ta có các giải pháp phù hợp. Trong số các giải pháp đó, nâng cao nhận thức xã hội cần phải được xem xét đầu tiên và coi là quan trọng nhất vì nhận thức là bước đi đầu tiên hình thành nên hành động của người dân liên quan đến di sản.

${ }^{1}$ http://www.nhandan.com.vn/vanhoa/item/35384602-phat-trienben-vung-gia-tri-di-san-the-gioi-o-viet-nam.html cập nhật ngày 27 tháng 6 năm 2018 


\section{1. Đối tựng tăng cuò̀ng nhận thức về vai trò và tầm quan trọng của di sản thế giới}

Nâng cao nhận thức trước hết phải hướng tới đối tượng quản lý và hoạt động văn hóa. Ở trường hợp cụ thể là Việt $\mathrm{Nam}$, việc phát triển văn hóa, bảo tồn và phát huy giá trị di sản phụ thuộc rất nhiều vào nhóm đối tượng này. Khi các nhà quản lý, những người hoạt động trong lĩnh vực văn hóa hiểu được vị trí, tầm quan trọng của di sản thế giới, họ sẽ có chiến lược, kế hoạch, phân bổ nguồn lực phù hợp để các di sản thế giới phát triển hết các tiềm năng sã̃n có của mình. Một di sản thế giới không phải đồ trang trí trên vương miện mà thực sự là tài sản vô giá của cộng đồng, địa phương. Nếu không biết khai thác, di sản đó mãi mãi chỉ là tiềm năng. Nếu khai thác không đúng, thậm chí sai lầm, các di sản đó có thể trở thành gánh nặng, hay hậu quả tai hại lâu dài đối với một vùng đất. Nhiều ví dụ về việc khai thác di sản quá mức khiến cho cộng đồng địa phương bị quá tải, ô nhiễm môi trường, bạo lực, tệ nạn xã hội gia tăng cho chúng ta bài học đắt giá về việc sử dụng di sản và vai trò nhận thức của các nhà quản lý, hoạt động văn hóa trong lĩnh vực này. Ở chính nước ta, việc đổ đất lấn biển trong vùng di sản Hạ Long để xây dựng các khu du lịch, khu đô thị, hay khai thác các dịch vụ trong hang động, phá núi khai thác đá, khai thác đánh bắt hải sản trong vùng di sản tại tỉnh Quảng Ninh là những ví dụ cho thấy sự lúng túng trong nhận thức của các nhà quản lý trong việc bảo vệ và phát huy giá trị di sản thế giới.

Nâng cao nhận thức của cộng đồng cũng là một giải pháp hết sức quan trọng. Cộng đồng chính là chủ nhân của các di sản nhưng không phải lúc nào, ở đâu, họ cũng có hiểu biết đầy đủ về giá trị hay cách thức để chăm sóc di sản của chính mình. Thông thường, sau khi được UNESCO vinh danh, các cộng đồng thường khai thác di sản để phát triển kinh tế - xã hội cho địa phương mình. Du lịch là một hoạt động được chú ý nhiều nhất. Đúng là du lịch “cung cấp cả những lợi ích có thể thấy ngay trước mắt như lợi nhuận từ thuế và thu nhập, và cả những lợi ích không thể thấy ngay được như sự tái sinh niềm tự hào của cộng đồng và một hình ảnh tốt về địa danh ấy"2. Tuy vậy, không phải lúc nào du lịch cũng đem lại lợi ích cho cộng đồng. Nhiều ví dụ cho thấy những người ở nơi khác đến, các doanh nghiệp bên ngoài đôi khi mới là những người được hưởng nhiều lợi ích từ việc công nhận di sản thế giới ở một địa phương. Tuy nhiên, bảo tồn di sản phải đem lại lợi ích cho cộng đồng thì việc bảo tồn

${ }^{2}$ Kim và các cộng sự, 2002, trang 128 mới bền vững. Nhà quản lý, những người kinh doanh di sản và người dân cộng đồng cần ý thức về tính bền vững trong khai thác di sản này để tránh khai thác di sản kiểu tận diệt. Một số di sản bị UNESCO rút danh hiệu vì không bảo vệ và phát huy giá trị đúng mực thung lũng Elbe ở Dresden (Đức), đền thờ Arabian Oryx (Ô-man)... là những ví dụ để các cộng đồng lưu ý khi phát huy giá trị di sản.

Du khách đến với các di sản thế giới cũng là đối tượng cần được nâng cao nhận thức về giá trị di sản. Như chúng ta đã đề cập, một trong những mục đích quan trọng của việc công nhận di sản thế giới là đem lại lợi ích kinh tế cho địa phương sở hữu di sản. Du lịch có thể giúp hiện thực hóa mục tiêu đó. CraigSmith và French "trong khi cả môi trường tự nhiên và nhân tạo là những sức hút quan trọng đối với du khách thì đó cũng không phải là những nguyên nhân duy nhất để khiến họ đi du lịch. Một trong những lôi cuốn lớn nhất đối với mọi người mong muốn đi du lịch từ những giai đoạn đầu là tìm hiểu văn hóa dân gian và phong tục của những người khác tồn tại ra sao"³. Di sản thế giới cung cấp những câu chuyện và hiểu biết mà du khách mong muốn đó. Vấn đề nhận thức đặt ra ở đây là, những câu chuyện gì được kể, không được kể, những việc gì nên làm, không nên làm ở các di sản thế giới đối với du khách. Về phương diện kinh tế thị trường, khai thác di sản là làm mọi việc đáp ứng nhu cầu đa dạng của du khách; tuy nhiên, di sản thuộc về lĩnh vực văn hóa, mà văn hóa cần có lôgic riêng của nó mà không nhất thiết phụ thuộc vào nhu cầu của du khách. Trước đây, chúng ta đã từng nghe thấy "sáng kiến" kể chuyện Ngũ Hành Sơn ở Đà Nã̃ng liên hệ với chuyện Tây Du Ký để thu hút khách Trung Quốc; Chúng ta cũng từng nghe thấy việc hướng dẫn viên Trung Quốc thuyết minh không đúng sự thật về lịch sử Việt Nam. Ở phạm vi nước ngoài, khi đến khu du lịch đảo Bali, vào những đền thờ Hindu giáo, tất cả du khách phải quấn khăn quanh người để tỏ lòng tôn kính với tín ngưỡng cư dân địa phương. Tất cả những ví dụ đó cho thấy rằng, du khách cần có những thông tin dù đa dạng nhưng phải chính xác về lịch sử một vùng đất, một di sản; họ cần có những ứng xử phù hợp với phong tục, tập quán, tín ngưỡng của một địa phương. Chính vì vậy, nâng cao nhận thức đối với đối tượng đặc biệt này giúp cho chúng ta bảo vệ di sản một cách tốt hơn. (Dù nhiều người cho rằng làm như vậy sẽ hạn chế du khách, cản trở sự tự do thể hiện của du khách

${ }^{3}$ Craig-Smith, S., and French, C., (1995) Learning to live with

Tourism, Melbourne, Longman House, trang 126 
nhưng tôi cho rằng, chính việc làm như vậy, và nhiều khi hạn chế nhu cầu của du khách, đã tạo ra sự hấp dẫn cho di sản thế giới, giúp địa phương lựa chọn được đối tượng du khách phù hợp, tránh du lịch bình dân. Đây có thể là gợi ý cho phát triển du lịch Sơn Đoòng!).

2.2. Hình thức tăng cường nhận thức về vai trò và tầm quan trọng của di sản thế giới

Thứ nhất, các phương tiện truyền thông đại chúng vẫn được xem là công cụ truyền thông, nâng cao nhận thức hữu hiệu về vai trò và tầm quan trọng của di sản. Trên thực tế, các phương tiện truyền thông đại chúng của Việt Nam đã có tương đối nhiều chương trình quảng bá di sản cả ở trong và ngoài nước. Nhiều chương trình truyền thông thực sự có chất lượng, giúp nâng cao nhận thức của người dân về di sản thế giới. Tuy nhiên, không phải vì thế mà chúng ta không còn việc gì để làm với truyền thông trong hoạt động tuyên truyền, nâng cao nhận thức về di sản. Giải pháp với truyền thông ở đây là cần gia tăng hơn nữa các chương trình truyền thông về di sản ở tất cả các loại hình truyền thông khác nhau, đặc biệt là trên các phương tiện truyền thông mới. Khi hiện nay người dân, đặc biệt là giới trẻ dành hầu hết thời gian theo dõi thông tin trên các phương tiện truyền thông mới, qua các mạng xã hội thì việc tuyên truyền trên các phương tiện này càng trở nên bức thiết hơn bao giờ hết. Các trang website giới thiệu di sản, tương tác với người sử dụng Internet, ứng dụng giải pháp dữ liệu lớn của cuộc cách mạng công nghiệp 4.0 để tạo ra diện mạo mới cho di sản, khiến di sản thế giới gần gũi với công chúng hơn là một giải pháp hữu hiệu.

Thứ hai, chú trọng hơn nữa giáo dục di sản ở nhà trường, tại các thiết chế văn hóa như bảo tàng, thư viện, nhà văn hóa, sinh hoạt cộng đồng... Lôgic ở đây là, di sản thế giới cũng cần có một thị trường khách hàng hiểu biết và ngày càng phát triển. Giáo dục di sản giúp tạo ra một tầng lớp công chúng hiểu biết về di sản, và khi công chúng hiểu biết, họ sẽ yêu di sản và ứng xử đúng, phù hợp với di sản. Hiện nay, trong các trường học, việc đi dã ngoại, các buổi học ngoại khóa đến với các di sản, trong đó có di sản thế giới đang ngày càng trở nên phổ biến hơn. Tuy nhiên, thay vì mang tính tự phát, hoạt động này nên trở thành thường kỳ để tạo ra nhận thức, hiểu biết về di sản cho học sinh. Những ví dụ về học sinh ở Nhật thường xuyên đi xem kịch ở các nhà hát Kabuki và Noh, có những buổi học về nhạc dân tộc khi còn rất nhỏ có thể là bài học về tăng cường nhận thức, hình thành khác giả đối với các di sản thế giới ở Việt Nam.

Thứba, hình thức tuyên truyền tại chỗ. Các di sản thế giới tự thân nó đã là những bài học lịch sử, văn hóa đối với mọi người đến với di sản. Nâng cao nhận thức đối với vai trò và tầm quan trọng của di sản ở chính tại địa điểm di sản chính là hình thức tuyên truyền phù hợp, gần gũi và thiết thực nhất đối với công chúng. Những người đến với Hội An có thể hiểu rõ hơn về lịch sử vùng đất, trải nghiệm trực tiếp về văn hóa, trang phục, ẩm thực của vùng đất di sản này, từ đó, giúp họ thêm yêu di sản. Cũng tương tự như vậy, một bài học về lịch sử thời kỳ Ngô Quyền, Phùng Hưng sẽ có sức hấp dẫn hơn nếu mọi người được cùng nhau trải nghiệm không khí của làng cổ Đường Lâm. Và cũng như thế, nghe cồng chiêng Tây Nguyên tại chính vùng đất này sẽ kích thích trí tò mò, tình yêu của du khách đối với vùng đất đại ngàn đầy nắng và gió. Những kiến thức thực địa như vậy sẽ giúp mọi người dễ nhớ, dễ yêu các di sản thế giới tại Việt Nam.

\section{Kết luận}

Nâng cao nhận thức của xã hội về vai trò và tầm quan trọng của di sản là một giải pháp quan trọng để bảo tồn và phát huy giá trị của các di sản thế giới, để di sản thực sự đóng vai trò vừa là mục tiêu, vừa là động lực cho sự phát triển kinh tế - xã hội và văn hóa của một địa phương. Tuy nhiên, ngành văn hóa, du lịch không thể thực hiện nếu thiếu sự phối hợp của các cấp, các ngành và các địa phương trong việc bảo tồn và phát huy giá trị di sản thế giới. Có được sự đồng tâm, nhất trí này, chúng ta sẽ bảo vệ bền vững các di sản thế giới, giúp đất nước phát triển phồn vinh trong tương lai.

\section{TÀI LIỆU THAM KHẢO}

1. Craig-Smith, S., and French, C., (1995) Learning to live with Tourism, Melbourne, Longman House;

2. Kim, K. Uysal, M. and Chen, J. (2002) Festival visitor motivation from the organizers' point of view. Event Management, Vol.7, 127-134;

3.http://www.nhandan.com.vn/vanhoa/item/35384602 -phat-trien-ben-vung-gia-tri-di-san-the-gioi-o-vietnam.html cập nhật ngày 27 tháng 6 năm 2018. 


\section{Solutions to improve social awareness on the role and importance of world heritage}

\section{Bui Hoai Son}

\section{Article info}

Recieved:

20/7/2018

Accepted:

10/9/2018

Keywords:

World Heritage, heritage

travel, cultural management,

community.

\begin{abstract}
Currently, Vietnam has been recognized with many UNESCO World Heritage. However, the recognition of a heritage is only the initial stage, the preservation and promotion of the heritage values, in order to contributes significantly to the socio-economic development is considered to be meaningful service for the sustainable development of the country. From the analysis of the importance of the World Heritage, the paper focuses primarily on the social awareness of the role of world heritage in the socio-economic development of the world heritage in a local place in particular and nationwide in general, from the basic questions such as: Raise awareness of whom? Or how to raise awareness?
\end{abstract}

